\title{
Clinical Outcomes of Management of Traumatic Cataract in a Tertiary Care Centre.
}

\author{
Anu Radha Bharti ${ }^{1}$, Pallavi Sharma ${ }^{1}$, Sachit Mahajan², Bhavani Raina ${ }^{3}$, Sanjay Kai ${ }^{4}$
}

1. Senior resident, Upgraded Department of Ophthalmology, Government Medical College, Jammu.

2. Junior Resident, Upgraded Department of Ophthalmology, Government Medical College, Jammu

3. Lecturer Upgraded Department of Ophthalmology, Government Medical College, Jammu.

4. Professor, Upgraded Department of Ophthalmology, Government Medical College, Jammu

Corresponding address: Dr. Sachit Mahajan, Lane No. 2 (Down), Greater Kailash, Jammu, Jammu and Kashmir, India. 180011. Ph +91-9419238870

Email: mahajansachit1992@gmail.com

DOI : 10.47799/pimr.0802.07

\section{ABSTRACT}

Background and Objectives : Ocular trauma can lead to development of cataract when natural lens is damaged by either blunt or penetrating injury. The management of traumatic cataract follows the same principle as for senile cataract but associated damage to ocular tissues and several post-operative complications may lead to suboptimal visual outcome. This study was conceptualized to evaluate the visual outcomes following management of traumatic cataracts.

Material and Methods : This prospective, longitudinal study was conducted on 80 patients with traumatic cataract in tertiary care centre. Patients were managed surgically and were followed up for a period of six months. Visual acuity was measured at every follow-up visit and any post-operative complications were noted and managed, accordingly. Final visual acuity was assessed at the end of six months.

Results: Maximum cases of traumatic cataract (53.75\%) were observed in age group of $<20$ years with male to female ratio of 2.63:1. Maximum patients (92.15\%) were implanted posterior chamber intraocular lens, either as a primary or secondary procedure. Uveitis and posterior capsular opacification were most common post-operative complications (30\%) and $68.75 \%$ cases achieved a final visual acuity of $6 / 6-6 /$ 18 at the end of six months.

\section{Conclusions}

Traumatic cataract is an important cause of ocular morbidity specially in young patients. Surgery in cases of traumatic cataract can yield good visual outcomes if posterior segment is not involved and if post-operative complications are managed efficiently.

Key words: Cataract; Eye injuries; Visual Acuity; Intraocular Lens; Cataract Extraction.

\section{Background and objectives}

Trauma is a major cause of unilateral blindness and visual impairment worldwide. 1 The World Health Organization (WHO) has estimated that 55 million ocular injuries occur each year, out of which 750000 people require hospitalization. 2 The prevalence of ocular trauma has been estimated to be around $2.4 \%$ in India.3 Ocular trauma can lead to development of cataract when natural lens is damaged by either blunt or penetrating injury. The management of traumatic cataract follows the same principle as for senile cataract but associated damage to ocular tissues may lead to compromise the final visual acuity. 4 Several post-operative complications like inflammation, corneal scarring, secondary glaucoma, pupillary capture, posterior capsular opacification, macular edema and retinal scarring may lead to suboptimal visual outcome.5-9 Keeping in view the complications associated with management of traumatic cataracts, this study was conceptualized to evaluate the visual outcomes following management of traumatic cataracts, in a effort to generate evidence for managing traumatic cataracts more effectively.

\section{Materials and Methods}

This prospective, longitudinal study was carried out over a period extending from December 2018 to March 2020 in a tertiary care teaching hospital after obtaining appropriate ethical clearance from Institutional Ethics Committee.

This study included 80 patients of traumatic cataract as a result of ocular injury from blunt or penetrating injury Patients who fulfilled the following criteria were included in the study and a written informed consent was taken from all the study participants after explaining the purpose of the study.

Inclusion criteria:

Patients above 5 years age and of either gender, having traumatic cataract due to blunt or penetrating injury.

\section{Exclusion criteria:}

1. Patients less than five years of age.

2. Traumatic cataract with retained intraocular foreign bodies, vitreous haemorrhage, retinal detachment.

3. Cases with corneal laceration $>10 \mathrm{~mm}$.

4. Cases with anterior segment injuries like iridodialysis, zonular dehiscence, gross pupillary distortion. 
After admission to the hospital, detailed occur history regarding age, mode of injury, cause of injury, time and place of injury was recorded. Pre-operative best corrected visual acuity (BCVA) was recorded with Snellen visual acuity chart. Extraocular movements, detailed slit lamp examination of anterior segment, pupillary reflexes, intraocular pressure (IOP) were recorded. Dilated fundus examination with indirect ophthalmoscopy and B-scan ultrasound was also done.

Keratometry, axial length measurement with ultrasound biometer and intra-ocular lens (IOL) power calculation was done.

All cases were underwent surgery under local or general anaesthesia. Small incision Cataract Surgery (SICS) with posterior chamber IOL implantation, primary lens aspiration at the time of wound repair with primary or secondary IOL implantation were performed. Patients were started on topical steroids, cycloplegics and topical antibiotics postoperatively and were discharged on second day after the surgery. Patients were followed up after five days, once a week for next six weeks and then monthly for six months. On every follow-up visit, visual acuity and IOP were recorded, detailed slit lamp biomicroscopy was done to rule out any complications. Posterior segment evaluation with indirect ophthalmoscopy was also done.

All the data was entered into Microsoft excel and subsequently analyzed.

\section{Results}

In this study, $53.75 \%$ patients were $<20$ years of age, followed by $31.25 \%$ patients between $21-40$ years of age and $15 \%$ patients $>40$ years of age, with age range of 7-60 years. The male to female ratio was $2.63: 1$ with $71.25 \%$ males.

Majority of patients (65\%) had penetrating injury 35\% had blunt injury. The most common causative agent were wooden objects $(65 \%)$ like sticks, arrows; followed by metallic objects (17.5\%) like wires. (Figure 1) table 1.

Visual acuity at the time of presentation is shown in

The morphology of cataract is shown in figure 2 .

The time interval to surgery was less than 1 month in $22(27.5 \%)$ cases, between 1-3 months in 36 (45\%) cases, 4-6 months in $14(17.5 \%)$ cases and more than six months in 8 $(10 \%)$ cases.

Fifty nine $(73.75 \%)$ cases underwent SICS with IOL implantation as standard procedure. $16(20 \%)$ cases, which had ruptured anterior lens capsule underwent primary lens matter aspiration. 9 cases out of these, underwent primary IOL implantation, and 7 cases underwent secondary $\mathrm{IOL}$ implantation. Five cases remained aphakic. The type of IOL implanted in patients is shown in figure 3.
Various intraoperative and postoperative complications during surgery is shown in table 2

In patients with severe posterior capsular opacification, Nd:YAG capsulotomy was done in 16 (20\%) cases.

The final visual outcome of patients at the end of six months is presented in table 3
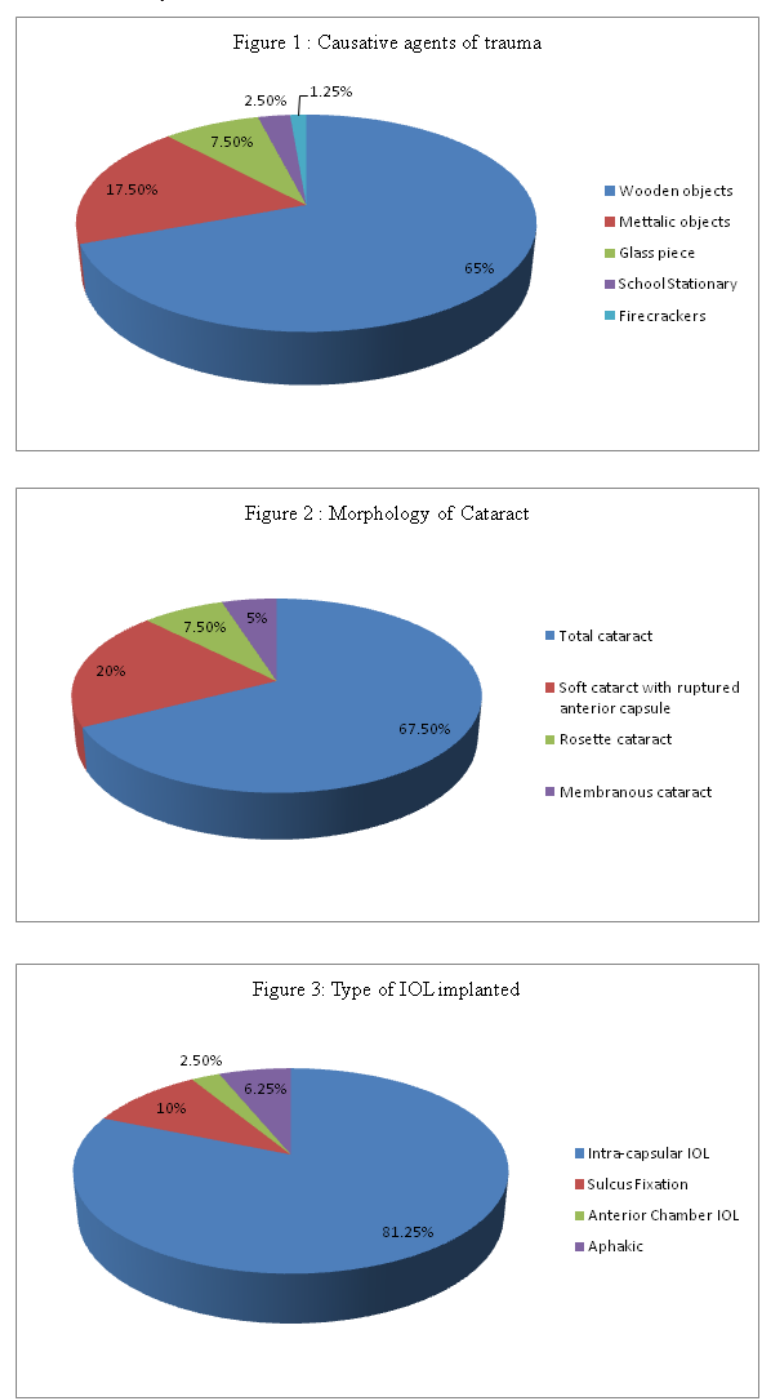

Table 1: Visual acuity at the time of presentation

\begin{tabular}{|l|c|c|}
\hline Visual acuity & $\mathrm{n}$ & percentage \\
\hline$>6 / 60$ & 4 & $5 \%$ \\
\hline $1 / 60-6 / 60$ & 20 & $25 \%$ \\
\hline Counting fingers & 5 & $6.25 \%$ \\
\hline Hand movements & 7 & $8.75 \%$ \\
\hline Perception of light & 44 & $55 \%$ \\
\hline
\end{tabular}


Table 2 : Intra-operative and post-operative complications encountered during surgery

\begin{tabular}{|l|c|c|}
\hline Compliactions & $\mathrm{N}$ & Percentage \\
\hline Intra-operative & 5 & $6.25 \%$ \\
\hline Vitreous loss & 3 & $3.75 \%$ \\
\hline Hyphema & & \\
\hline Post-operative complications & 7 & $8.75 \%$ \\
\hline Increased IOP & 24 & $30 \%$ \\
\hline Uveitis & 5 & $6.25 \%$ \\
\hline Pupillary capture & 24 & $30 \%$ \\
\hline Posterior capsular opacification & 8 & $10 \%$ \\
\hline Macular edema & 7 & $8.75 \%$ \\
\hline Corneal edema & 5 & $6.25 \%$ \\
\hline Hyphema & & \\
\hline
\end{tabular}

Table 3: Final Best corrected visual acuity at the end of six months

\begin{tabular}{|l|c|c|}
\hline Visual acuity & N & Percentage \\
\hline $6 / 6-6 / 18$ & 55 & $68.75 \%$ \\
\hline $6 / 24-6 / 60$ & 22 & $27.5 \%$ \\
\hline$<6 / 60$ & 3 & $3.75 \%$ \\
\hline
\end{tabular}

\section{Discussion}

In present study, $53.75 \%$ were under 20 years of age with male to female ratio of $2.63: 1$. Sofi IA et al, reported that $50 \%$ patients were $<20$ years of age and $32.5 \%$ patients were in the age group of 21-40 years, with a male to female ratio of 3:1 in their study. ${ }^{10}$ Similarly, Zaman $\mathrm{M}$ et al reported maximum patients $(50 \%)$ in the age group of $5-15$ years, with male to female ratio of $8.6: 1{ }^{11}$ Bhandari $\mathrm{AJ}$ et al, reported that maximum patients (38\%) were in the age group of 26-35 years, with male to female ratio of $1.5: 1 .^{12}$ Panda $A$ et al reported maximum patients (31.25\%) in the age group of $15-24$ years and $21.42 \%$ patients in the age group of $35-44$ years, with male to female rato of $2.5: 1 .^{13}$ Young males are more commonly affected with ocular trauma due to their involvement in outdoor and sports related activities.

Penetrating injuries were common (65\%) as compared to blunt injuries (35\%) in our study. Similar findings have been reported by Memon $\mathrm{MN}$ et al, who reported $68.3 \%$ cases of penetrating injuries, ${ }^{14}$ Sofi IA et al, who reported $62.5 \%$ cases of penetrating injuries ${ }^{10}$ and Synder $A$ et al, who reported $78.6 \%$ cases of penetrating injuries. ${ }^{15}$ Staffieri SE et al, reported $88 \%$ cases due to penetrating injuries, ${ }^{16}$ which is much higher than

\section{our study.}

Maximum cases of injuries were caused by wooden objects (65\%) in our study. Similar observations have been made by Shah $\mathrm{M}$ et al, who reported $56.4 \%$ cases of injuries caused by wooden objects and ${ }^{17}$ Memon $\mathrm{MN}$ et al, reported $31.7 \%$ cases of injuries by wooden stick and $17.1 \%$ cases caused by stone. ${ }^{14}$ Whereas, Zaman $\mathrm{M}$ et al, reported $19.48 \%$ cases of injuries by stone, ${ }^{11}$ in their study.

Ahmed $\mathrm{N}$ et al reported $50 \%$ cases with visual acuity of hand movements ${ }^{18}$ and Kumar $S$ et al reported maximum cases (85.96\%) with visual acuity of perception of light ${ }^{19}$ which is similar to our study, where maximum patients (55\%) had visual acuity of perception of light, followed by visual acuity of $1 / 60$ $6 / 60$ in $25 \%$ cases.

With regards to morphology of cataract, Panda A et al, reported $74 \%$ cases with total cataract, ${ }^{13}$ Shah $\mathrm{M}$ et al, reported $59.9 \%$ cases with soft cataract and $26.6 \%$ cases with total cataract. ${ }^{17}$ Sofi IA et al, reported $67.5 \%$ cases with total cataract, soft cataract with ruptured anterior capsule in $24 \%$ cases, and rosette cataract in $8 \%$ cases, ${ }^{10}$ which is similar to our study with $67.5 \%$ patients with total cataract and $20 \%$ patients with soft cataract.

In our study $90 \%$ patients were operated with six months, with $72.5 \%$ cases undergoing surgery within three months and $27.5 \%$ cases undergoing surgery within a month. Eckstein $\mathrm{M}$ et al reported that $56 \%$ patients underwent surgery within a month and $87 \%$ patients in 6 months. 20 Zaman $M$ et al, reported that $22.07 \%$ cases underwent surgery within a month and $35.06 \%$ cases underwent surgery in 1-3 months.11 Memon $\mathrm{MN}$ et al, reported that $41.5 \%$ patients underwent surgery in 1 month and 39\% patients in 1-6 months. ${ }^{14}$ All these studies are in corroboration with our study.

Regarding surgery, Panda $\mathrm{A}$ et al reported $\mathrm{PCIOL}$ implantation in $77.6 \%$ cases, $^{13}$ Kumar $S$ et al reported PCIOL implantation in $97 \%$ cases $^{19}$ and Memon MN et al, reported 95.12\% cases with PCIOL implantation, ${ }^{14}$ similar to our study where $81.25 \%$ cases had intra-capsular IOL implantation and $10 \%$ cases had sulcus fixation of IOL. Most common postoperative complications in our study were uveitis (30\%) and posterior capsular opacification (30\%). Similar rates of complications have been observed by Synder A et al, uveitis in $30.9 \%$ cases, $^{15}$ Loncar VL et al, corneal edema in $8.3 \%$ cases, hyphema in $4.16 \%$ cases, uveitis in $20.83 \%$ cases and 21 Zaman $M$ et al, PCO in $23.37 \%$ cases, anterior chamber inflammation in $25.97 \%$ cases, hyphema in $3.89 \%$ cases. ${ }^{11}$ Patients with uveitis were managed with topical steroids and cycloplegics and patients with increased IOP were given anti-glaucoma medications depending on the rise of IOP from baseline. $\mathrm{Nd}$ :YAG capsulotomy was done in $20 \%$ cases due to severe posterior capsular opacification. Sofi IA et al, reported that $17.5 \%$ cases needed capsulotomy due to thick PCO, in their study. 


\section{Anuradha Bharti, et al}

Final visual outcome was favourable in most cases with $68.75 \%$ cases achieving visual acuity of 6/6-6/18 in our study. Memon $\mathrm{MN}$ et al, reported that $70.8 \%$ cases achieved visual acuity of $>6 / 18$ in their study. ${ }^{14}$ Eckstein $\mathrm{M}$ et al, observed that $67 \%$ patients achieved visual acuity of $>6 / 12,20$ Zaman $M$ et al, reported visual acuity of $6 / 6-6 / 12$ in $68.83 \%$ cases $^{11}$ and Kumar $\mathrm{S}$ et al, reported $71.9 \%$ cases with visual acuity of 6/6-6/ $18,{ }^{19}$ corroborating well with our study.

\section{Conclusion}

Thus, we conclude that traumatic cataract is an important cause of ocular morbidity specially in young patients. Penetrating injuries most commonly lead to development of traumatic cataract. Surgery in cases of traumatic cataract with posterior chamber IOL implantation can yield good visual outcomes if posterior segment is not involved and if postoperative complications are managed efficiently.

\section{Conflicts of interest: None}

Acknowledgements: Our sincere thanks to all the patients for their support and compliance during follow-up of this study.

Source of funding: None

Ethical Approval: Institutional ethics Committee, Government Medical College.

\section{REFERENCES}

1. Katz J, Tielsch JM. Lifetime prevalence of ocular injuries from the Baltimore eye survey. Arch Ophthalmol $1993 ; 111: 1564-8$

2. Ngrel AD, Thylefors B. The global impact of eye injuries. Ophthalmic Epidemiol 1998;5:143-69.

3. Vats S, Murthy GV, Chandra M, Gupta SK, Vashist P, Gogoi M. Epidemiological study of ocular trauma in an urban slum population in Delhi, India. Indian J Ophthalmo 2008:56:313-6.

4. Kuhn F, Morris R, Witherspoon CD, et al. The birmingham eye trauma terminology system (BETT). J Fr Ophtalmol 2004;27(2):206-10.

5. Bekibele CO, Fasina O. Visual outcome of traumatic cataract surgery in Ibadan, Nigeria. Niger J Clin Pract 2008;11(4):372-5.

6. Koenig SB, Ruttum MS, Lewandowski MF, et al. Pseudophakia for traumatic cataracts in children. Ophthalmology 1993;100(8):1218-24.

7. Mohammadpour M, Jafarinasab MR, Javadi MA. Outcomes of acute postoperative inflammation after cataract surgery. Eur J Ophthalmol 2007;17(1):20-8.

8. Hemo Y, BenEzra D. Traumatic cataracts in young children. Correction of aphakia by intraocular lens implantation. Ophthalmic Paediatr Genet 1987;8(3):203-7. www. pimr.org.in

9. Awner S, Buckley EG, DeVaro JM, et al. Unilateral pseudophakia in children under 4 years. J Pediatr Ophthalmol Strabismus 1996;33(4):230-6.

10. Sofi IA, Bharti AR, Gupta SK, et al. Visual outcome and post-operative complications of traumatic cataract. J. Evolution Med. Dent. Sci. 2016;5(38):2307-10.

11. Zaman M, Iqbal S, Sanaullah, et al. Frequency and visual outcome of traumatic cataract. J Postgrad Med Inst 2006;20(4):330-4.

12. Bhandari AJ, Jorvekar SA, Singh $P$, et al. Outcome after cataract surgery in patients with traumatic cataract. Delta J Ophthalmol.2016;17:56-8.

13. Panda A, Kumar S, Das $\mathrm{H}$, et al. Striving for the perfect surgery in traumatic cataract following penetrating trauma in tertiary care hospital in eastern Nepal. J Nepal Med Assoc 2007;46(167):119-25.

14. Memon MN, Narsani AK, Nizamani NB. Visual outcome of unilateral traumatic cataract. J Coll Physicians Surg Pak 2012;22(8):497-500.

15. Synder A, Kobielska D, Omulecki W. Intraocular lens implantation in traumatic cataract. Klin Oczna 1999;101(5):343-6.

16. Staffieri SE, Ruddle JB, Mackey DA. Rock, Paper and scissors? Traumatic pediatric cataract in Victoria 1992 2006. Clin Experiment Ophthalmol 2010;38(3):237-41.

17. Shah MA, Shah SM, Shah SB, et al. Morphology of traumatic cataract: does it play role in final visual outcome. BMJ Open 2011;1(1):e000060. doi: 10.1136./ bmjopen2011-000060.

18. Ahmed N, Aziz T, Akram S. Visual outcome after primary IOL implantation for traumatic cataract. Pak J Ophthalmol. 2011;27(3):152-54

19. Kumar S, Panda A, Badhu BP, et al. Safety of primary intraocular lens insertion in unilateral childhood traumatic cataract. J Nepal Med Assoc 2008;47(172):179-85

20. Eckstein M, Vijayalakshmi P, Killedar $M$, et al. Use of intraocular lenses in children with traumatic cataract in south India. Br J Ophthalmol 1998;82(8):911-5.

21. Loncar VL, Petric I. Surgery treatment, clinical outcomes, complications of traumatic cataract: retrospective study. Croat Med J 2004;45(3): 310-3.

How to cite this article : Bharti $A$, Sharma $P$, Mahajan $S$, Raina B, Kai S. Clinical Outcomes of Management of Traumatic Cataract in a Tertiary Care Centre. Perspectives in Medical Research 2020; 8 (2):20-23

DOI : 10.47799/pimr.0802.07

Sources of Support: Nil, Conflict of interest: None declared 